\title{
IMAGE-BASED 3D MODELING VS LASER SCANNING FOR THE ANALYSIS OF MEDIEVAL ARCHITECTURE: THE CASE OF ST. CROCE CHURCH IN BERGAMO
}

\author{
A. Cardaci ${ }^{\text {a }}$ A. Versaci ${ }^{\text {b }}$
}

${ }^{a}$ Dept. of Engineering, University of Bergamo, Italy - alessio.cardaci@unibg

${ }^{\mathrm{b}}$ Faculty of Engineering, Architecture and M.S., University "Kore" of Enna, Italy - antonella.versaci@ unikore.it

\section{Commission VI, WG VI/4}

KEY WORDS: image-based 3D modelling, laser scanning, cultural heritage, documentation, conservation, colour

\begin{abstract}
:
The Church of St. Croce in Bergamo (second half of the 11th century), is a small four-sided building consisting of two overlapping volumes located in the courtyard adjacent to the Bishop's Palace. In the last years, archaeological excavations have unearthed parts of the edifice, until that time hidden because buried during the construction of the Basilica of Santa Maria Maggiore and now restored its original form. Due to the recent discoveries, a critical review of all the existing documentation in order to clarify the relationship of the various building components has been considered necessary. A quick, well-timed, chromatically characterized and accurate survey aimed at the complete digital reconstruction of this interesting example of medieval Italian architecture was then needed. This has suggested simultaneously testing two of the most innovative technologies: the 3D laser scanning survey ensuring high-resolution and complete models within a short time, and the photogrammetric automatic image-based modelling, allowing a three-dimensional reconstruction of the architectural objects. This paper intends to show the results achieved by the analytical comparison between the two methodologies, and thus analyse their differences, the advantages and the deficiencies of both of them and the opportunities for future enhancements and developments.
\end{abstract}

\section{INTRODUCTION}

Nowadays, it is becoming increasingly clear that cultural heritage represents one of the major resources for sustainable and endogenous development. Actually, cultural heritage is an important asset for our economy, because it constitutes a key reference point for the improvement of both national identity and human and social capital. This sector is going through a phase of rapid growth due to, among other things, the incessant improvement of new techniques applied to the survey, documentation, cataloguing, valorisation and transmission of cultural heritage. Tools which are more and more accessible to operators, but, at the same time, requiring a much wider range of knowledge, skills and competencies for their selection and integration in accordance with the pursued objectives.
That is the context in which the case study presented here and concerning the Church of Santa Croce in Bergamo, is located. Thanks to its antiquity, its particular planivolumetric layout (central plan based) and title (factors leading to the complex historiographical theme of "copies" of the medieval Holy Sepulchre), in a few decades, the church has raised the interest of researchers from different backgrounds who have interpreted in different ways, both its conformation and function, as its chronology. Since both the cathedral area and that closest to S. Croce have recently been archaeologically investigated, bringing to light interesting elements, a critical review of all existing documentation has become essential, in order to clarify the articulation of the various building components and this on the basis of a coherent stratigraphic succession (Fig. 1). However, to address in a correct way the interpretative

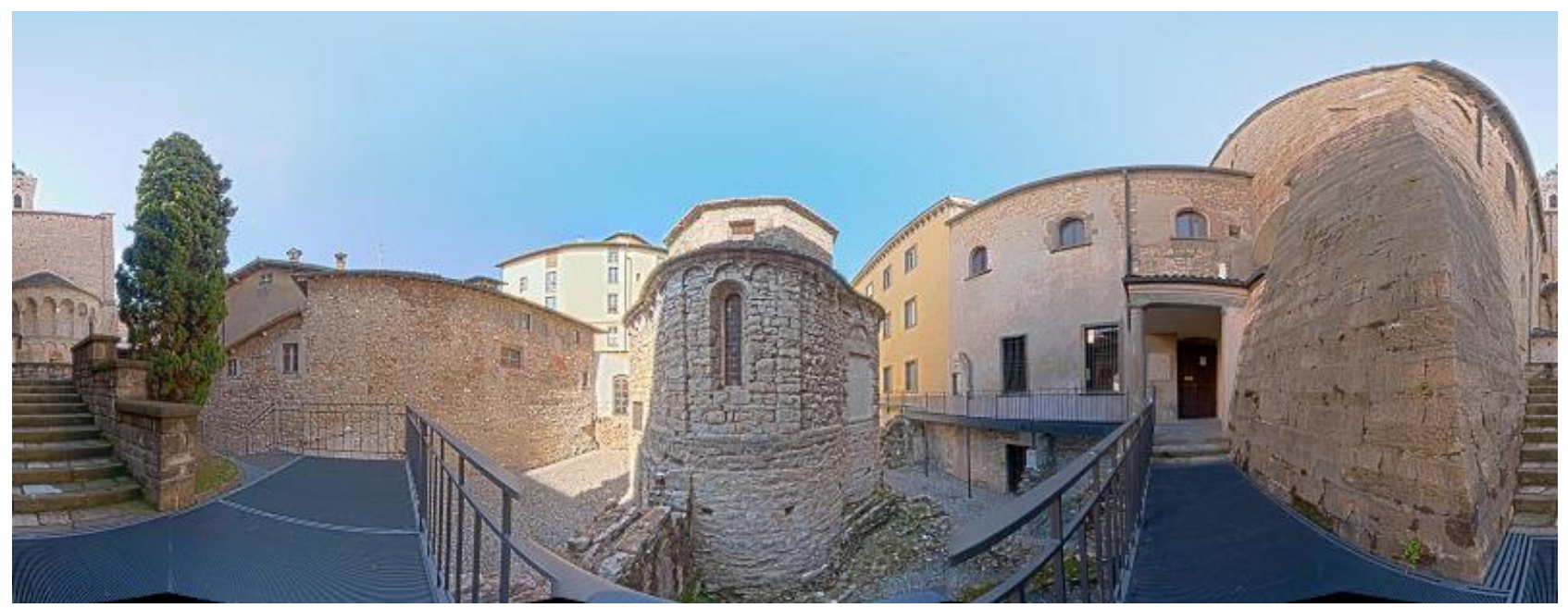

Figure 1. A spherical image of the St. Croce church in Bergamo 
problems related to the atypical church structure and to its historical stratification, a survey carried out by traditional instruments (or - worse - simplified on the basis of abstract typological plan models) has been considered inadequate, due to the specific characteristic of the early Romanesque buildings generally based on their executive irregularities.

Consequently, since a reliable model of the church was required, it has been decided to set up the analysis by laser scanning, which usefulness has been largely tested in many fields - prior in tasks of historical documentation, as-built documentation, etc. - showing the advantages offered by this methodology in terms of point acquisition speed, accuracy, manageability and time-saving, in comparison with other surveying techniques. Moreover, thanks to the newest generation of registration software, the time needed for post processing is dramatically minimized.

On the other end, if laser scanner survey is able to provide very accurate metrics information - ensuring, in the case of historic buildings the easy delimitation and a proper dimensional evaluation of areas and volumes - it does not consent an exact identification of the historical/architectural elements, yet. This is due to the high but not optimal colour quality of the cloud and then of the orthographic projections, obtained using the pictures taken by the camera integrated to the instrument.

In recent years, however, new technologies allowing the threedimensional reconstruction of the architectural objects from images, has been developed. Although perhaps not so metrically accurate as laser scanning, they permit to generate relatively dense point clouds, characterized by a much higher colour quality. The 3D models so obtained, ensure an easy recognition of the stratigraphic units as well as an eloquent display of degradation and collapse phenomena. The high speed and simplicity of use of 3D image-based software and their low cost, make this procedure a viable alternative to other practices, all much more expensive in terms of hardware and software (Remondino et al., 2012; Fassi et al., 2013).

This work intends to compare the results obtained with these two methodologies and to identify the challenges and benefits of using them, even on integrated basis.

\section{THE CHURCH OF SANTA CROCE IN BERGAMO}

The small chapel of Santa Croce in Bergamo, located in the historical centre of the upper town not far from Piazza Vecchia in the courtyard of the Diocesan administration, between the Bishop's Palace and the Basilica of Santa Maria Maggiore, is immersed in a centuries-old context which recently rediscovered important historical and archaeological remains. It is characterized by a particular quatrefoil layout and a tiburio, and spread over two levels, free of internal communication as divided by a vaulted system. The upper floor, internally frescoed, is punctuated by pilaster strips connected by a series of three small arches in brick and equipped with two splayed single lancet windows; the stratigraphic analysis has highlighted a portal on the west side, today walled up. The lower floor, devoid of pilaster strips, has a door at the level of the medieval floor and two rectangular windows. The regularity of the plan is not clearly detectable as interrupted by a long wall that existed prior to construction.

The church is now fully visible thanks to the archaeological excavations carried out in recent years (Ghiroldi, 2006; Fortunati, Vitali, 1999-2000; Ghiroldi, 2007) and that have "unearthed" the lower floor, bringing the planking level to that of the early middle ages. The landfill was probably made in the second half of the Vth century to adjust the allocation of the new courtyard to the levels imposed by amendments to the nearby cathedral during its construction, as it was for a portion of the rooms of the adjacent medieval bishop's palace (Calzana, Caccia, 2008). In the modern age, new buildings were built onto the church, so hiding upstairs in their overall configuration and remaining therefore unconsidered in the classic studies of Fernand De Dartein (De Dartein, 1865-1882) and Arthur Kingsley Porter (Porter, 1916). A first step to "rediscover" the chapel was made in the 30s of the last century by Luigi Angelini as part of its restructuring plan for Bergamo Alta (Angelini 1940, 1963; Angelini, 1989), when "the pickaxe demolished the last superstructures that disfigured and compressed the church" (Angelini, 1940), but only the recent excavations have allowed to see the church as, probably, was originally (Fig. 2).

The investigated archaeological stratification has shown that the Santa Croce's foundations rest on the remains of some buildings from Roman times, the walls of which have been shortened, but nothing has been revealed about the late antique and early medieval phases, with the exception, a few meters away, of a building (almost certainly a church, having regard to its position), kept intact for a portion of the elevation, which hidden part supports the south-western edge of Santa Maria. It is clear that the church of Santa Croce was built in the centre of the area, at that time free from existing buildings, over the masonry aqueduct that fed the fountain of Antescolis adjacent to the Cathedral of Santa Maria and which wall is clearly visible on the ground floor of the chapel.

In the course of the Angelini's restoration works, the courtyard floor was probably lowered, as well as the "small dome". This has been testified by the recognition of a previous drip line, so attributing the elevation to a remake of 1561 , as it appears from a documentary source. The roofs have been completely redone and, during the removal of the upper one, three fragments of capitals (that Angelina interpreted as belonging to the medieval mullioned windows) were found. Plasters were removed and the joints of the outer walls were completely "passed through" concrete and the masonry integrated on the basis of a mimetic intent that now make it difficult to clarify its stratigraphy.

\section{THE AUTOMATIC SURVEY: A PRECIOUS TOOL FOR THE ANALYSIS OF MEDIEVAL ARCHITECTURE}

The Romanesque architecture of the It and XIIth centuries in many cases does not manifest itself with strict geometrical constructions. It was customary that the construction of smaller buildings did not follow a defined project (at least as understood in the modern sense, based on metric drawings and giving clear indication about implementation phases). This was because "a general outline to start activities was not necessary, given that, from time to time, the builder proceeded in laying, by adapting what it was available and looking for the best combinations" (Cagnana, 2000).

It is plausible that the church of Santa Croce results from an initial idea of space due to a building with more than one axis of symmetry, based on a centre (the vertical axis of the building) with respect to which, the four circumferences that draw the quatrefoil plant are tangent. However, the construction phase, although roughly following this setting, has not strictly adhered to it: the circumferences are rounds having variable radius and curvature, the alignments appear random and rather than straight lines they most look like uncertain and swaying lines. The same unitary idea of space that binds outside the plant and the elevations based on a ratio of $2 / 3$, is contradicted inside by the arched floor that divides the church into two areas (Fig. 3). This contrast between geometric "model" and as-built, testifies of a widespread practice that started the building construction from an initial idea, but left wide open to possible variants 
(including substantial ones) and full freedom of choice to master carpenters in the building phase (Chiovelli, 2006).

Because of the differences between the "ideal" model of the church of Santa Croce and the building actually built, it has therefore been necessary to facilitate its reading and understanding by the means of "automatic survey". Actually, traditional survey - whether direct or instrumental - leave the operator the opportunity to make some alternative interpretations of geometry, mediated through its knowledge and culture, which are inevitably very far from the symbolic and the analogical medieval mentality.

The choice of the points to measure (i.e., the selection of what is "to measure" and what, instead, can be neglected) occurs since the early stage of the eidotype drawing: sketches necessary in the traditional survey methodology to transfer "on the paper" the measures time to time performed. Moreover, in the schematization of plans, sections and elevations is already configured an idea of geometry, regularized and hierarchically organized between the parties deemed most important. Conversely, a sort of inability of the measuring instrument to make "intelligent" choices characterizes the automatic survey. The laser scanner detects all that is around it and to it visible, but did not really "see" what to measure and cannot distinguish which parts of the building are to be considered "interesting". Each element is interpreted as a simple sequence of points spaced, more or less, constantly between them. Ultimately, a tool for automatic acquisition does not have the human capacity to interpret shapes and geometries and is able to return, then, orthographic projections and/or cross-section, such as simple sequences of points, not conditioned by a previous and perhaps erroneous interpretation of the monument spatiality.

\subsection{A first experience: the laser scanning survey of the church of Santa Croce}

The 3D laser scanning is performed through multiple "scans" carried out from as many stations located around the monument to survey.

A scan is a 3D representation of the object: a solid photograph that allows obtaining an image in which any pixel also provides the spatial position of each detail "read" by the instrument. One single scan cannot detect the entire building and cover it entirely, as in the photographic survey, it is necessary to take a series of images to appreciate all its aspects and eliminate possible shadow cones, revealing every hidden part.

In the framework of this survey method, even more than for the traditional ones, the planning phase, intended as a preparatory moment for in situ measurements, is of great importance. The use of laser scanning requires, in fact, a strict program of surveying. Special care has to be taken in establishing the correct position of the stations and of the targets essentials for the data processing and registration, as well as the distance between each scan and the resolution of each scan range, in order to obtain a point clouds able to totally "cover" the study object, limiting as possible, the areas of occlusion (GarcíaGomez et al., 2011; Bertocci, Bini, 2012).

In the case of Santa Croce, architectural structure characterized by a not particularly complex geometry, but irregular and marked by two interior spaces arranged on different levels and unrelated to each other, the planning have had to consider issues concerning the alignment (in the jargon, registration) of individual scans; in other words, the need to contain the error in the limits of a tolerance of the same order of magnitude of the measuring instrument (the scan of a surface must overlap at the end of the recording, not give rise to two different surfaces staggered between them).

The survey was developed by making acquisitions following a spiral path that, from inside the basement room has moved to close the upper floor. The campaigns were carried out in two sessions: the first, using the instrument FARO Photon 120 in May of 2011, and a second, in the month of June 2011 with the FARO Focus3D.

The certainly imposing size of the first instrument, devoid of an internal camera for the colour data acquisition and not deviceindependent, as well as the limitations imposed by a need for external battery supply, have considerably extended the working time. The need to then contain the scan number (10 scans have been realized: 8 external according to the four axes of symmetry and 2 internal), in view of time and cost saving and ease of use, has prompted the research group to repeat the experiment in order to gain a greater understanding of the monument and investigating it through innovative means.

Actually, the second instrumentation, albeit based on the same phase shift technology, it is much faster and more accurate, because it is capable of acquiring up to 976.000 points per second, with a distance accuracy up to $\pm 2 \mathrm{~mm}$ at $25 \mathrm{~m}$ and a greater reliability in the measurement repeatability thanks to a very precise tilt sensor $\left( \pm 0.02^{\circ}, 0.001^{\circ}\right.$, distance \pm 15$)$ for the self-compensation of the tool on the vertical axis. In addition, the small dimensions of the instrument $(24 \times 24 \times 10 \mathrm{~cm}$ and a weight of only $5 \mathrm{~kg}$ ) made it possible to speed up surveying operations and its placement in tight places: 24 scans (18 external and 6 internal) were, in fact, performed according to resolutions ranging between $1 / 4$ and $1 / 2$ of the maximum one (the average distance of the scanning step: $3 \mathrm{~mm}$ to $10 \mathrm{~m}$ ), with an average duration of 15 minutes each, including the acquisition of colour .

Measurements were carried out by means of "environmental acquisitions" at $360^{\circ}$, which helped to create the point cloud related not only to the church of Santa Croce, but also to the entire yard. The speed of data acquisition and measurement offered by this instrument is so high as to make it more affordable (in terms of reduction of working time) to collect all information and then clean the point clouds of unnecessary data, rather than to adjust the scanning angle and the resolution in each individual scan (Versaci, Cardaci, 2011).

So doing, in each scan were thus included also reference elements useful to the union of the same scans: fifty paper targets (mark checkerboard) combined with five calibrated spheres with magnetic base (mark registration spheres) placed at different heights, on and around the building and in points visible from more stations. The pre-alignment and the fine registration of the scans were performed with the software FARO Scene 5.1. The results obtained were very satisfactory from geometrical point of view, with an overlap error of o the individual scans of $0.38 \mathrm{~cm}$ and a standard deviation of 0.30 $\mathrm{cm}$.

If thanks to the used software, it was possible to quickly and easily produce 3D views of the model and orthographic projections, however, the images were "grainy": many coloured points side by side and without continuity, in which the areas of occlusion and the data not acquired, were represented as dots of the same colour as the background.

Together with the different chromaticity of each scans - visible especially in overlapping areas - these problems, thus, transform the colour component in an information more quantitative than qualitative, slightly reducing the efficacy of the laser scanning for stratigraphic analysis and conservation purposes (Fig. 4). 
3.2 A second experience: the automatic image-based 3d modelling for the church of Santa Croce's reconstruction

The software for automatic image-based modelling allow the easy creation of 3D models, starting from a sequence of images. On the net, there are free web service solutions not requiring installation: once the images are uploaded in a remote database, the 3D model is automatically implemented by an "on-line" software and then sent via e-mail to the applicant. Besides these already known systems, more recently, new semi-professional products appeared on the marked. For very low price, they are able to fulfil the most demanding user requirements. In 2010 , the software PhotoScan, produced by the Russian company Agisoft LLChas has implemented a solution for 64bit Windows systems, which through the import of .jpeg, .tiff, .png, .bmp or .mpo files, generates in semi-automatic mode (the user can intervene in the process by setting many input parameters) the three-dimensional textured mesh, mapped with the same pictures used to generate the model.

The reconstruction is performed following three main phases:

Step 01) The images are spatially aligned through a "structure from motion" (SFM) algorithm, which operates the threedimensional reconstruction of the scene starting from the recognition of a series of homologous points in two or more frames taken by a camera rotating around the scene. The points, geo-referenced into a single reference system, will compose the point cloud (not dense) that it is already possible to navigate and/or export;

Step 02) The spread cloud is transformed into a polygonal model whose points are the vertices of a mesh network that reconstitutes the geometric volume of the object. At this stage, the operator can select the algorithm to be used and adjust its parameters in order to choose how the points will be interpolated in the construction of the meshes;

Step 03) The polygonal model is mapped with textures extracted from photographs. The user can decide how to overlap the images depending on the desired outcome. A proper texture mapping mode selection helps to obtain optimal texture packing and, consequently, better visual quality of the final model. The mapping mode can be:

- Generic: this is the default mode. It allows parameterizing texture atlas for arbitrary geometry. No assumptions regarding the type of the scene to be processed are made; program tries to create as uniform texture as possible;

- Adaptive orthophoto: the object surface is split into the flat part and vertical regions. The flat part of the surface is textured using the orthographic projection, while vertical regions are textured separately to maintain accurate texture representation in such regions. When in the Adaptive orthophoto mapping mode, program tends to produce more compact texture representation for nearly planar scenes, while maintaining good texture quality for vertical surfaces, such as walls of the buildings.

- Orthophoto: the object surface is textured in the orthographic projection. The orthophoto mapping mode produces even more compact texture representation than the adaptive orthophoto mode at the expense of texture quality in vertical regions.

- Single photo: this procedure allows generating texture from a single photo. The photo to be used for texturing can be selected from texture from list.

The model can be exported in the most common formats (.stl., .wrl, .obj) at every stage (scattered cloud, mesh pattern, textured model). Moreover, it is always possible to enable/disable each image or parts of a photograph, and to import textures and meshes created using other applications.

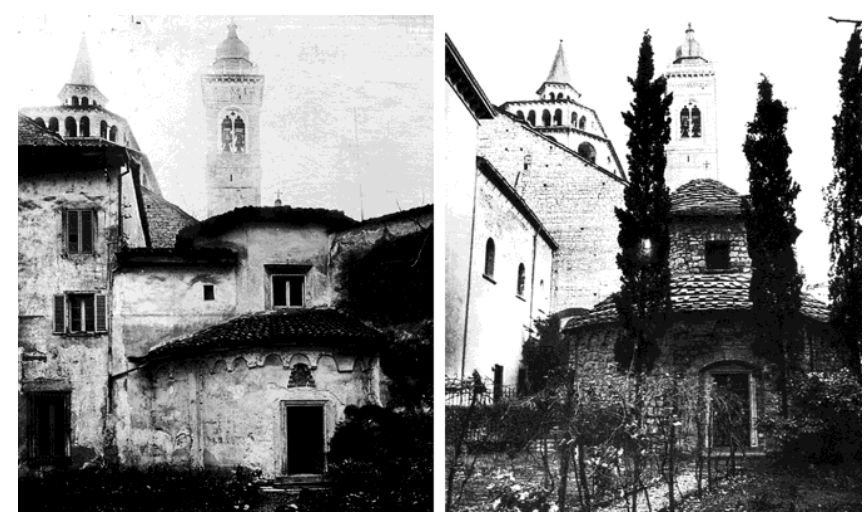

Fig. 2 The church before and after L. Angelini restoration's works
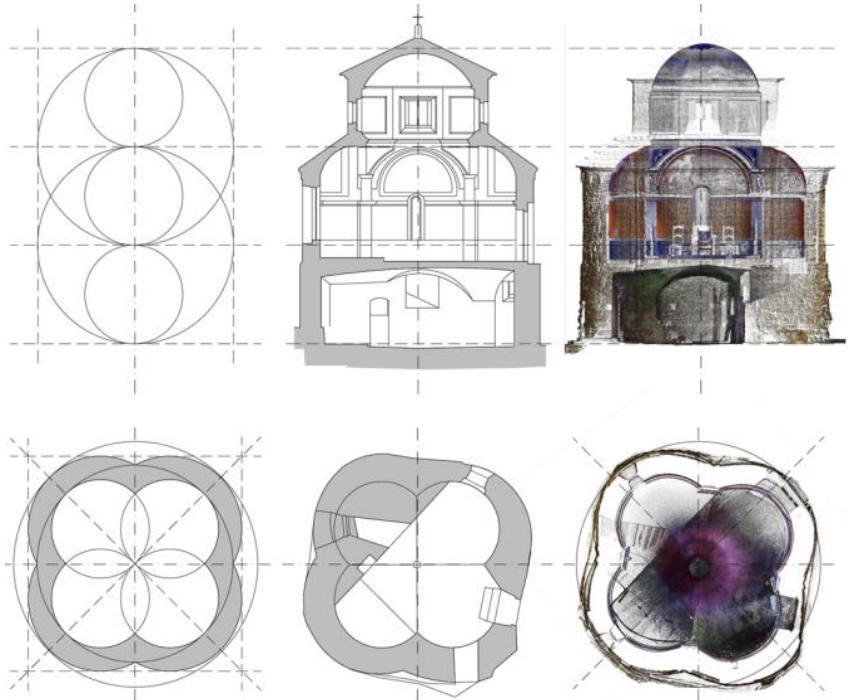

Fig. 3 Comparaison between the real model, the traditional survey and laser scanning
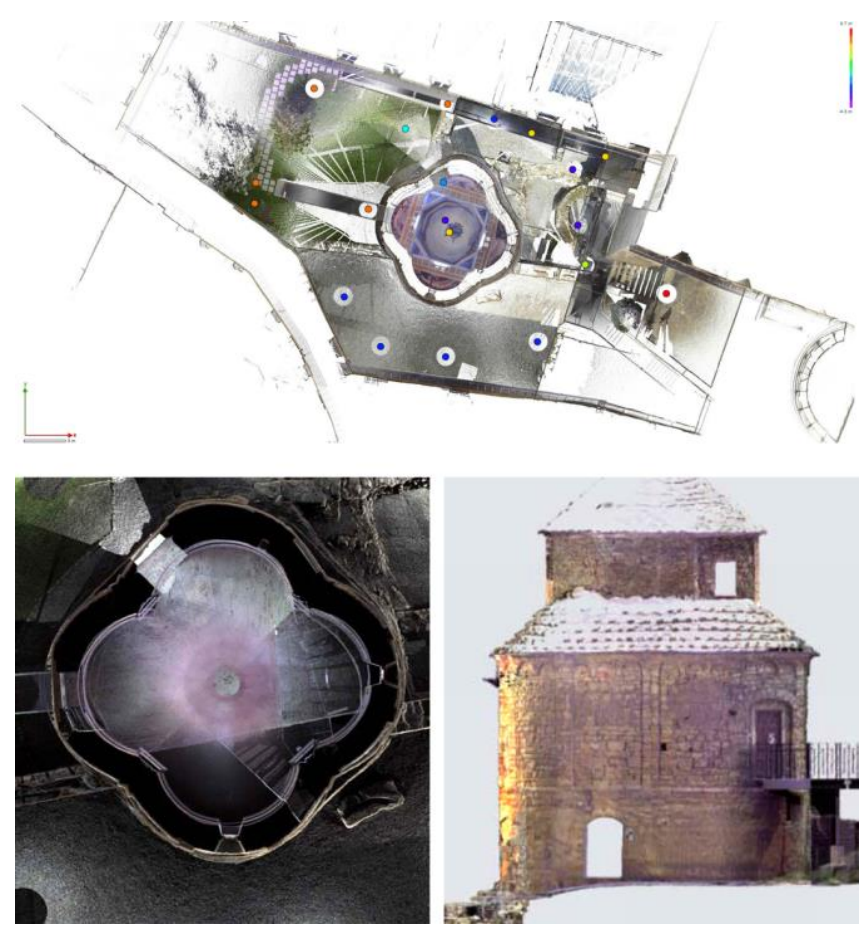

Fig. 4 The Laser Scanner survey and one of orthophotos generated 
The success of this procedure is strongly linked to the characteristics of the object (uniform colorations without contrast areas will allow the easy recognition of homologous points) and to the quality of the photographs taken (images out of focus and with little overlap will make difficult the reconstruction phase of the geometry by the algorithms of the software). The result, even starting from the same images, may also differ in how "random" is the automatic recognition of common points.

Prerequisites for optimum results are: the use of a good photographic camera, a well-planned (and attentive to the lighting) photographic campaign, a digital development of the frames in .raw format, a proper white point balance and a careful chromatic characterization (a common practice for a right photographic survey) combined with a proper calibration of the camera and of the optical sensing systems, necessary to eliminate the geometric deformations of the lens.

The photo acquisition planning phase established for the Church of Santa Croce, realized at the same time with laser scanning survey and based on careful coordination between the two methodologies, has been divided into three campaigns: one for the lower floor, the other for the upper floor and the third the longer and complex - for the outdoor area. In each campaign (limited in terms of time in order to have constant ambient lighting conditions) a photograph of the "colour checker white balance target" was firstly taken, to guarantee precise, uniform, neutral white in any successive shot and so going to eliminate the colour casts from photos (in this case-study, for the photo calibration, it has been used the X-Rite system). The whole process required 25 photographs for the lower floor of the site, 58 photographs for the upper level and 88 for the entire outdoor area (with the exception of the roofs). For this test, the camera employed was the Canon EOS 5D, equipped with a full-frame sensor of 21 megapixels and with a fixed focal length lens Canon $24 \mathrm{~mm} / \mathrm{f} 1.4$. The use of the .raw format and of the colour checker classic target allowed realizing, during the digital development, a DNG colour profile for the chromatic correction of the other images (Fig. 5).

\section{CONCLUSIONS}

This experience has confirmed the opportunity to integrate 3D laser scanning survey and the low-cost image based 3D modelling highlighting the convenience of a combined action between two methodologies on themselves based on different needs in terms of resources and costs as well as in performance characteristics.

The study of the geometry finalized to the analysis of exact proportions (or, as a result, to the finite element analysis) makes the laser scanner more suitable as it allows the fast acquisition of a tremendous amount of data. However, the often-complex geometry of the surveyed objects requires a heavy operator intervention to acquire and process data; it also assumes the availability of software capable of handling with high accuracy a large number of vertices and intricate wall geometries. Finally, the presence of a digital camera coupled to the instrument, allows to simultaneously recording both texture and metric data, but this approach does not always achieve optimal results as the ideal condition for the photographs taking does not necessarily coincide with that of the laser. Usually, multiple scans of the object are needed in order to reproduce the entire geometry without gaps and/or areas hidden by overhanging structures (Fig. 6).

However, material, stratigraphic and degradation phenomena analysis and visualisation require, more than the correct definition of the metric model with sub-centimetre accuracy, a
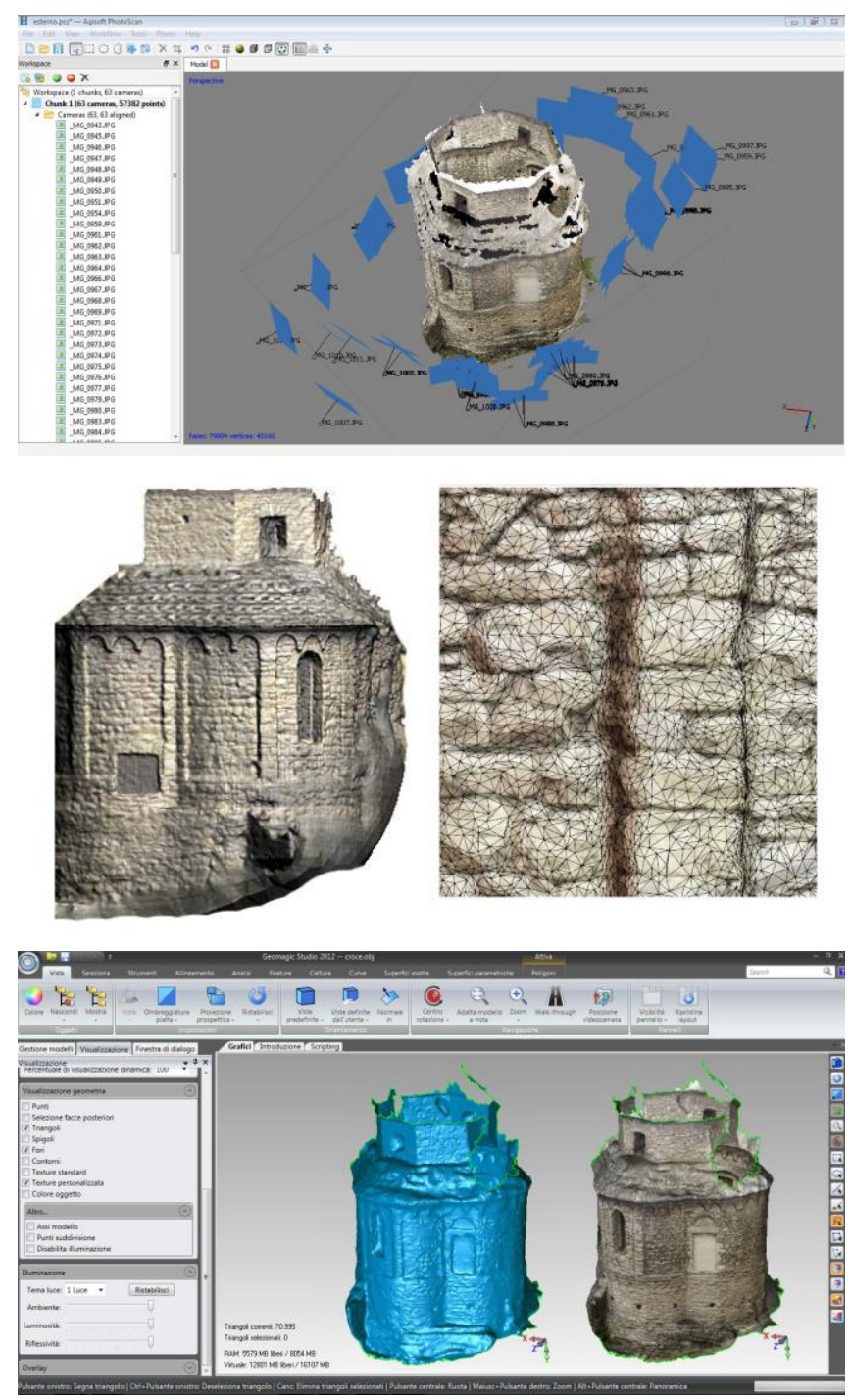

Fig. 5 The image-based model
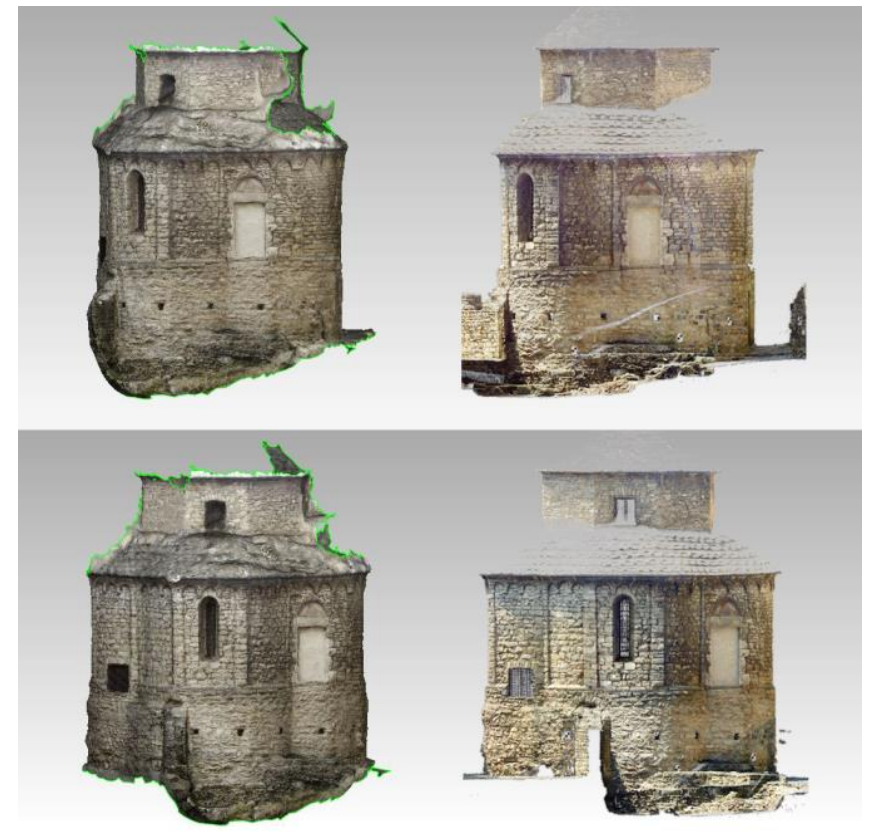

Fig. 6 A comparison between the orthophotos obtained by 3D image-based modelling and laser scanning 
perfect recognition of the structural parts, only possible through highly realistic images. The image-based techniques are perhaps better suited to this exigency being able to avail now, thanks to the advancement of technology, low cost digital and high quality restitution systems. In this work, the experiment carried out with a low-cost software, has showed the effectiveness of the image-matching algorithms for the generation of digital surface model, suitable for the purpose of the orthographic rectification (elevations and architectural profiles) and networked visualization with WebGL technology.

In particular, despite the high degree of automation reducing the control and operator intervention (even non-existent in applications based on remote server processing as Autodesk 123D Catch or Viztu Technologies Hypr3D or the older ARC 3D Webservice developed by the VISICS research group of the K.U. Leuven), the quality of results achieved is anyway so high to make often unnecessary a subsequent post-editing. Nevertheless, the models are not very reliable from metrical point of view, being affected by errors exceeding 3-5 times the fault tolerance, because the automatic detection of homologous points on different images causes the creation of scattered point cloud models from which derive DSM not fully responding to the real monument.

In this test, the high accuracy achieved by the metric survey of the building has made it possible to relate without hesitation the interiors on two levels with the outside, confirming the accurate plan layout of the upper building and providing some answers about the geometry of the lower floor and on its relationship with the existing buildings. It provided information on the general state of conservation and allowed to identify critical situations and to assess the need for conservation actions. Even more important, it has been an invaluable tool for any other indepth analysis. To make it easier to represent and in order to facilitate a more eloquent and immediate stratigraphic investigation, the technique of image based $3 \mathrm{D}$ modelling has played a substantial role in order to integrate information acquired.

The development of 3D image-based software is fast and continuous. It aims at better combining ease of use and model accuracy, to time not yet acquired. Some software houses have introduced the markers automatic recognition, a very useful feature to the final object's reconstruction.

\section{ACKNOWLEDGEMENTS}

This work is part of a research cooperation activity carried out with the Curia Vescovile of Bergamo. Activities have been carried out in collaboration with the University of Enna, Laboratory for the Restoration of Cultural and Artistic heritage. The authors are thankful to Dario Gallina Ph.D. for the work carried out on the stratigraphic analysis out and for the precious historical information provided about the Church.

\section{REFERENCES}

Remondino, F., Del Pizzo, S., Kersten, T., Troisi, S., 2012. Low-Cost and Open-Source Solutions for Automated Image Orientation - A Critical Overview. Lecture Progress in Cultural Heritage Preservation. Notes in Computer Science. 7616, pp. 40-54.

Fassi, F., Fregonese, L., Ackermann, S., De Troia, V., 2013. Comparison between laser scanning and automated $3 \mathrm{~d}$ modelling techniques to reconstruct complex and extensive cultural heritage areas. In: The International Archives of the Photogrammetry, Remote Sensing and Spatial Information
Sciences, Vol. XL-5/W1, 2013 3D-ARCH 2013 - 3D Virtual Reconstruction and Visualization of Complex Architectures, 25 - 26 February 2013, Trento, Italy, pp. 73-80.

Ghiroldi, A. 2006, Gli scavi. In: Fortunati, M. (ed.) 2006, Medioevo a Bergamo. Archeologia e antropologia raccontano le genti bergamasche, Truccazzano (MI), pp. 25-27.

Fortunati, M., Vitali, M., 1999-2000, Bergamo, Cappella di Santa Croce. Le strutture ipogee tra età romana e medioevo. In: Notiziario della Soprintendenza per i Beni Archeologici della Lombardia, pp. 199-202

Ghiroldi, A. 2007, La Cappella di Santa Croce in Bergamo. In: Fortunati, M. e Poggiani Keller, R. (ed.), Storia economica e sociale di Bergamo. I primi millenni. Dalla preistoria al Medioevo, II, Bergamo, Fondazione per la Storia Economica e Sociale di Bergamo - Istituto di Studi e Ricerche, pp. 534-538

Calzana, P., Caccia, B. 2008, Attorno a Santa Croce. In: La Rivista di Bergamo, 54.

De Dartein, F., 1865-1882, Étude sur l'architecture lombarde et sur les origines de l'architecture romano-byzantine, [ristampa in facsimile], Como, 1963

Porter, A.K., 1916, Lombard Architecture, II - Monuments. Abbazia di Albino, Milan, New Haven, Yale University Press

Angelini L. 1940, Scoperte e restauri di edifici medievali in Bergamo alta, «Palladio. Rivista di Storia dell'Architettura», a. IV, pp 35-43.

Angelini, L., 1963, I lavori compiuti per il Piano di Risanamento di Bergamo Alta, 1936-1943, 1950-1960, Bergamo, Stamperia Conti

Angelini, S. (ed.), 1989, Bergamo: Città Alta. Una vicenda urbana, Bergamo, Comune di Bergamo

Cagnana, A, 2000, Un graffito di cantiere dagli scavi del Duomo di S. Andrea a Venzone (UD). In: Brogiolo, G.P., Atti del II Congresso Nazionale di Archeologia Medievale, Musei Civici, Chiesa di Santa Giulia, Brescia, 28 settembre - 1 ottobre 2000, Firenze, Edizioni all'Insegna del Giglio, pp. 389-394.

Chiovelli, R., 2006, Tecniche costruttive murali medievali. La Tuscia, Roma, L'Erma di Bretschneider

Garcia-Gómez I., Fernández De Gorostiza M., Mesanza Moraza A., 2011, Láser escáner y nubes de puntos. Un horizonte aplicado al análisis arqueológico de edificios. In Arqueología de la Arquitectura, 8, pp. 25-44

Bertocci, S., Bini, M. 2012, Manuale di rilievo architettonico e urbano, Novara, CittàStudi Edizioni

Versaci, A., Cardaci, A., 2011, Il rilievo "automatico" del colore: nuove tecnologie a supporto della lettura cromatica per il restauro dell'edilizia storica. In: Il colore nel costruito storico. Innovazione, sperimentazione, applicazione, Lerici, 13 ottobre 2011, Rome: Aracne Editrice, pp. 1-7 